\title{
Anti-inflammatory drugs and uterine cervical cancer cells: Antineoplastic effect of meclofenamic acid
}

\author{
ALEJANDRO D. SORIANO-HERNANDEZ ${ }^{1,2}$, DANIELA MADRIGAL-PÉREZ ${ }^{1}$, \\ HECTOR R. GALVAN-SALAZAR ${ }^{1,2}$, MARGARITA L. MARTINEZ-FIERRO ${ }^{3}$, LAURA L. VALDEZ-VELAZQUEZ ${ }^{4}$, \\ FRANCISCO ESPINOZA-GÓMEZ ${ }^{1}$, OSCAR F. VAZQUEZ-VUELVAS ${ }^{4}$, BERTHA A. OLMEDO-BUENROSTRO ${ }^{1}$, \\ JOSE GUZMAN-ESQUIVEL ${ }^{5}$, IRAM P. RODRIGUEZ-SANCHEZ ${ }^{6}$, AGUSTIN LARA-ESQUEDA ${ }^{2}$, \\ DANIEL A. MONTES-GALINDO ${ }^{1,4}$ and IVAN DELGADO-ENCISO ${ }^{1,2}$
}

\begin{abstract}
${ }^{1}$ School of Medicine, University of Colima, Colima, Colima 28030; ${ }^{2}$ Cancerology State Institute, Colima State Health Services, Colima, Colima 28000; ${ }^{3}$ Molecular Medicine Laboratory, Academic Unit of Human Medicine and Health Sciences, Autononous University of Zacatecas, Zacatecas, Zacatecas 98160; ${ }^{4}$ School of Chemistry, University of Colima, Coquimatlán, Colima 28400; ${ }^{5}$ General Hospital of Zone No. 1, Mexican Institute of Social Security, Colima, Colima 28000;

${ }^{6}$ Department of Genetics, School of Medicine, Nuevo Leon Autonomous University, Monterrey, Nuevo León 64460, Mexico
\end{abstract}

Received August 29, 2014; Accepted May 22, 2015

DOI: $10.3892 / 01.2015 .3580$

\begin{abstract}
Uterine cervical cancer (UCC) is one of the main causes of cancer-associated mortality in women. Inflammation has been identified as an important component of this neoplasia; in this context, anti-inflammatory drugs represent possible prophylactic and/or therapeutic alternatives that require further investigation. Anti-inflammatory drugs are common and each one may exhibit a different antineoplastic effect. As a result, the present study investigated different anti-inflammatory models of UCC in vitro and in vivo. Celecoxib, sulindac, nimesulide, dexamethasone, meclofenamic acid, flufenamic acid and mefenamic acid were tested in UCC HeLa, VIPA, INBL and SiHa cell lines. The cytotoxicity of the drugs was evaluated in vitro. Celecoxib, sulindac, nimesulide, mefenamic acid and flufenamic acid presented with slight to moderate toxicity (10-40\% of cell death corresponding to $100 \mu \mathrm{M})$ in certain cell lines, while meclofenamic acid exhibited significant cytotoxicity in all essayed cell lines (50-90\% of cell death corresponding to $100 \mu \mathrm{M})$. The meclofenamic acid was tested in murine models (immunodeficient and immunocompetent) of UCC, which manifested a significant reduction in tumor growth and increased mouse survival. It was demonstrated that of the evaluated anti-inflammatory drugs, meclofenamic acid was the most cytotoxic, with a significant antitumor effect in murine models. Subsequent studies are necessary to evaluate the clinical utility of this drug.
\end{abstract}

Correspondence to: Dr Ivan Delgado-Enciso, School of Medicine, University of Colima, 333 University Avenue, Colonia Las Viboras, Colima, Colima 28030, Mexico

E-mail: ivan_delgado_enciso@ucol.mx

Key words: non-steroidal anti-inflamatory drugs, meclofenamic acid, antitumor activity, uterine cervical cancer, murine model

\section{Introduction}

Uterine cervical cancer (UCC) is one of the main causes of cancer-associated mortality in women. The main identified factor involved with disease development is chronic infection by high-risk human papilloma virus (HPV) (1). Prevention by vaccination and premalignant lesion treatment are the best tools for decreasing the incidence of this condition. However, the diagnosis of UCC at the advanced stages is frequent in developing countries. In these conditions, the existing treatments are not effective and affect the quality of life; as a consequence, the requirement for novel treatments continues to be necessary. Inflammation has been identified as a critical component during tumor proliferation, progression and dissemination $(2,3)$. Inflammation is induced and maintained mainly by the activity of the cyclooxygenase 2 (COX-2) enzyme, and as a result, its inhibition may be adequately employed for cancer treatments. Among the pharmaceuticals with high inhibition activity for COX-2, non-steroidal anti-inflammatory drugs (NSAIDs) are considered to play a significant role (1,4-6).

The chronic administration of different NSAIDs may contribute to reducing the incidence of diverse neoplasias (7) and these actions represent potential treatments. In this context, the fenamates, such as the meclofenamic acid, represent a group of the most potent NSAID COX-2 inhibitors. Meclofenamic acid is a phenamate derivative that is not only a potent inhibitor of aldoketoreductases (AKRs) (8), enzymes that regulate the androgen, estrogen and progestin concentration, but also catalyzes the reduction of ketosteroids (9). The exerted inhibition of the NSAIDs over these enzymes has been considered as a proposed mechanism of the antineoplastic effect (10). Several anti-inflammatories have also been probed experimentally as a UCC treatment, however, the obtained results were varied and it is difficult to establish the substance that has the greatest antineoplastic effect (11). In spite of the 
fact that meclofenamic acid has previously been proposed as a promising antineoplastic drug, the fenamates have not yet been investigated in UCC. The aim of the present study was to evaluate the antineoplastic effect of several NSAIDs, including the fenamates, in in vitro and in vivo assays of UCC.

\section{Materials and methods}

Cell lines and drugs. The cell lines used in the present study, which were supplied by the Health Sciences Research and Development Center of Nuevo Leon Autonomous University (Monterrey, Mexico), were the human UCC HeLa, VIPA, INBL $\left(\mathrm{HPV}-18^{+}\right)$and $\mathrm{SiHa}\left(\mathrm{HPV}-16^{+}\right)$cell lines, and the mouse TC-1 (HPV-16 $)$ cell line $(12,13)$, which were manipulated in a class II A2 laminar flow cabinet and maintained in Dulbecco's modified Eagle's medium (DMEM; Sigma-Aldrich, St. Louis, MO, USA) supplemented with $10 \%$ (v/v) fetal bovine serum (FBS; Gibco Life Technologies, Carlsbad, CA, USA) at $37^{\circ} \mathrm{C}$, with $5 \% \mathrm{CO}_{2}$ and $97 \%$ relative humidity $(14,15)$. Celecoxib, sulindac, nimesulide, meclofenamic acid, flufenamic acid and mefenamic acid were obtained as powder salts with a pureness of $98 \%$ (Sigma-Aldrich). The dexamethasone was acquired in solution for intravenous application (Chinoin Pharmaceutical Products, Aguascalientes, Mexico). Initially, the pharmaceutical salts were prepared in highly concentrated solutions. Celecoxib, sulindac and nimesulide were dissolved in dimethyl sulfoxide (Sigma-Aldrich), while meclofenamic acid was dissolved in ethanol at $70 \%$, mefenamic acid was dissolved in $0.1 \mathrm{M} \mathrm{NaOH}$ and flufenamic acid was dissolved in absolute ethanol (Sigma-Aldrich).

Cytotoxicity assay (in vitro). The cells were plated in 96-well plates (Corning Inc., Corning, NY, USA) at a density of $1 \times 10^{3}$ cells per well, containing DMEM with $2 \%$ FBS. Subsequent to an initial 12-h period, the cells were exposed to the different drugs (16) and incubated for 3 days. The cytotoxicity was determined with the Alamar Blue ${ }^{\circledR}$ reagent, according to the manufacturer's instructions (DIAsource ImmunoAssays, Nivelles, Belgium) (17). The cell viability was compared with untreated cells, which were considered to represent $100 \%$ viability. The assays were performed with two repetitions. In a first selection assay, celecoxib, sulindac, nimesulide, dexamethasone and meclofenamic acid were used in concentrations of $100 \mu \mathrm{M}$. In a subsequent assay, the fenamates, meclofenamic acid, flufenamic acid and mefenamic acid were used in concentrations of $0,7.5,15,30,60,120$ and $240 \mu \mathrm{M}$.

Murine model assays in UCC (in vivo). A total of $1 \times 10^{5}$ human HeLa [human papillomavirus (HPV)-18 ${ }^{+}$cells were injected in the dorsal region of immunodeficient Foxn1(nu) female mice (nude), aged 4-6 weeks (Harlan Mexico, Mexico City, Mexico). After 10-15 days, when the tumors reached a length of $4 \mathrm{~mm}$ (small tumors), the mouse population was divided into two groups: Control group (treatment with saline solution) and experimental group (treatment with meclofenamic acid). The intraperitoneal drug application was performed over 30 days, at a dose of $10 \mathrm{mg} / \mathrm{kg} /$ day (tolerated dose in humans and mice) in a volume of $100 \mathrm{ml}$ (16). The tumor was measured every 5 days up to completion of the 30-day treatment. In addition, a second assay was performed with two variations with respect to the previous experiments: i) A immunocompetent murine model was used; and ii) treatment was initiated when the tumors reached a larger size (a diameter of $10 \mathrm{~mm}$ ). A total of $4 \times 10^{5} \mathrm{TC}-1$ cells $\left(\mathrm{HPV}-16^{+}\right)$were injected into the dorsal region of $\mathrm{C} 57 \mathrm{Bl} / 6$ female mice (nude), aged 4-6 weeks (Harlan Mexico, Mexico City, Mexico). After 20-25 days, once the tumors had reached a diameter of $10 \mathrm{~mm}$ (large tumors), the mouse population was divided into a control group and an experimental group, to start the application of meclofenamic acid at the previously described dose for a period of 25 days, with measurements of the tumor every 3 days. The antitumor efficiency of meclofenamic acid was evaluated with the increment of the tumor volume and the survival curves. The tumor size was registered by measuring three dimensions (length, width and height) with a vernier gauge to compute the tumor volume, according to previously reported procedure (18). In consideration of the study protocols and ethics, the mice were sacrificed when the tumor reached $25 \mathrm{~mm}$ on any of its dimensions, following the Mexican norms (NOM-062-ZOO-1999) that regulate the use of laboratory animals $(19,20)$. The study was approved by the ethics committee of the State Cancer Institute of Colima, Colima, Mexico (Certificate of Ethical Approval: REV1/ANTICEL/2013).

Statistical analysis. The cytotoxicity data in the cell lines were analyzed by descriptive statistics. The tumor growth was analyzed by statistical techniques for curves of tumor growth with no parametrical methods (free distribution) (19). Mouse survival was analyzed by Kaplan Meier curves, with the MedCalc statistical program, version 10 for Windows Vista (MedCalc Software, Ostend, Belgium). $\mathrm{P}<0.05$ was used to indicate a statistically significant difference.

\section{Results}

Fig. 1A shows the viability of the different UCC cell lines exposed to different anti-inflammatory drugs. Meclofenamic acid exhibited the highest cytotoxicity in the presence of the four tested cell lines. Celecoxib, sulindac and nimesulide also presented with partial cytotoxic activity, but only in certain cell lines. To evaluate if the meclofenamic acid effect was similar to the other drugs, a second assay was carried out employing multiple concentrations in the SiHa, HeLa and TC-1 cell lines. Upon calculation of the necessary drug concentration lethal to $25 \%$ of cells $\left(\mathrm{LC}_{25}\right)$ (Fig. $1 \mathrm{~B}$ ), it was observed that meclofenamic acid required a lower concentration to generate the same level of cell death. The $\mathrm{LC}_{50}$ could not be calculated, as only meclofenamic acid induced $>50 \%$ cell death in all studied cell lines. This fact demonstrated that meclofenamic acid was the most cytotoxic drug among those studied, and the in vivo essays were consequently performed with this drug.

Two animal models with tumors associated with HPV were generated. The first model was immunodeficient with neoplasia of human HeLa HPV-18 ${ }^{+}$cells, in which treatment was started when the tumors were small (4 mm diameter). A second model was immunocompetent with neoplasia of murine TC-1 HPV- $16^{+}$cells, in which treatment was started when the tumors were large (10 $\mathrm{mm}$ diameter). As shown in Fig. 2A, the small tumor model using HeLa cells displayed a clear reduction in tumor growth starting from day 10 of the 

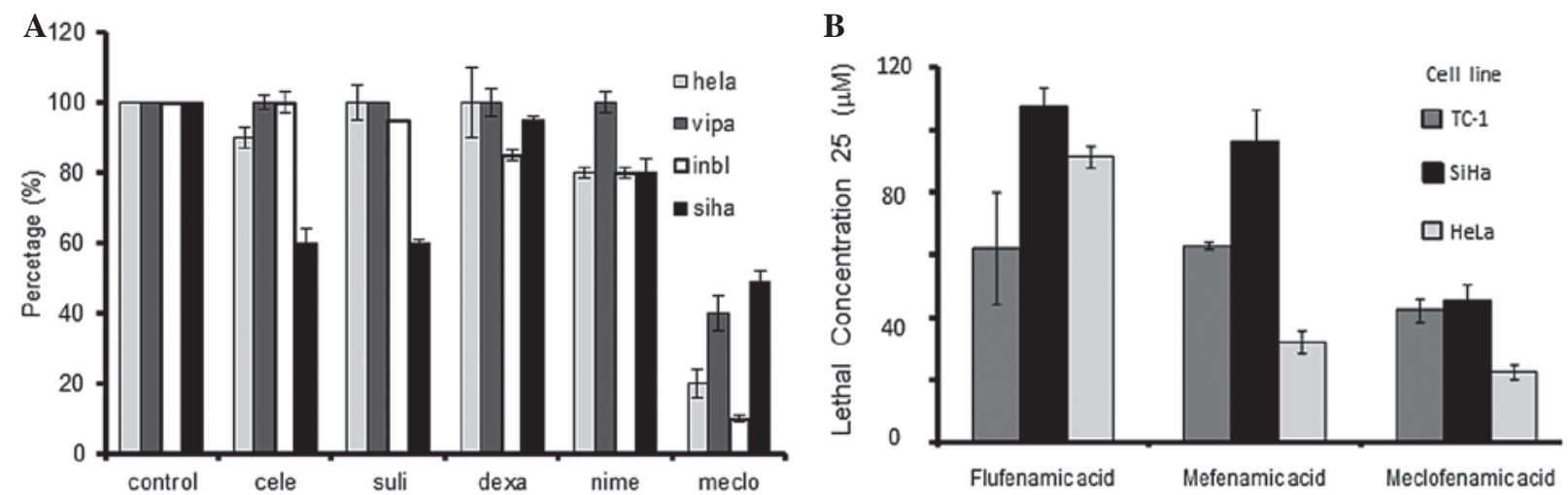

Figure 1. Percentage of cell viability after exposure of the 4 cell lines to $100 \mu \mathrm{M}$ of different anti-inflammatory drugs. (A), evidencing that the meclofenamic acid is the most that occasions cytotoxicity. In the same way, the fig. depicts that from the fenamates; (B) the meclofenamic acid requires the lowest concentration to produce the $25 \%$ of cell death (LC25). Celecoxib, cele; sulindac, suli; dexamethasone, dexa; nimesulide, nime; meclofenamic acid, meclo.

A

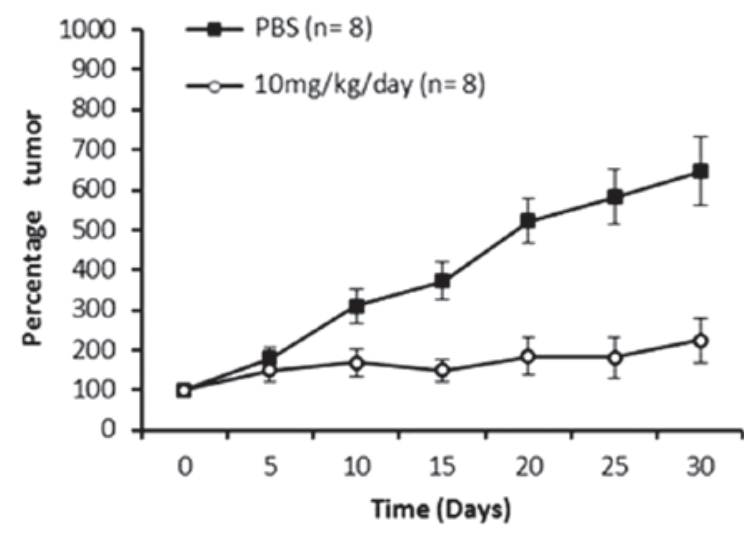

B

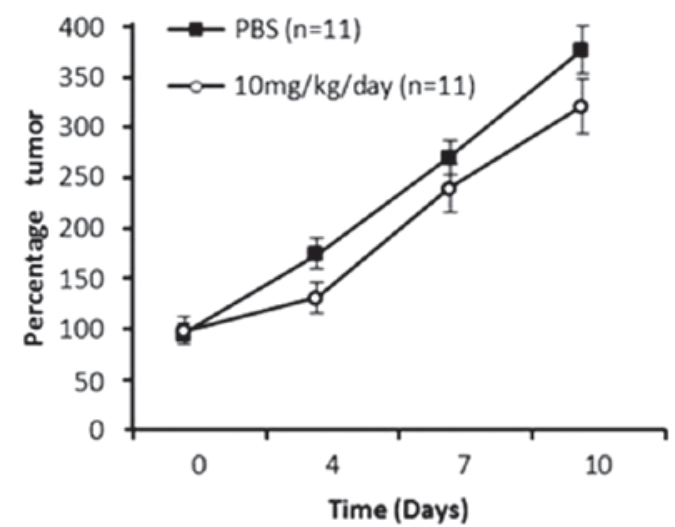

Figure 2. Tumor growth in the (A) immunodeficient murine model that started treatment when tumors were small (4 mm diameter), and in the (B) immunocompetent murine model that started treatment when the tumors were already large (10 mm diameter). In the two models, the administration of meclofenamic acid reduced the tumor growth.
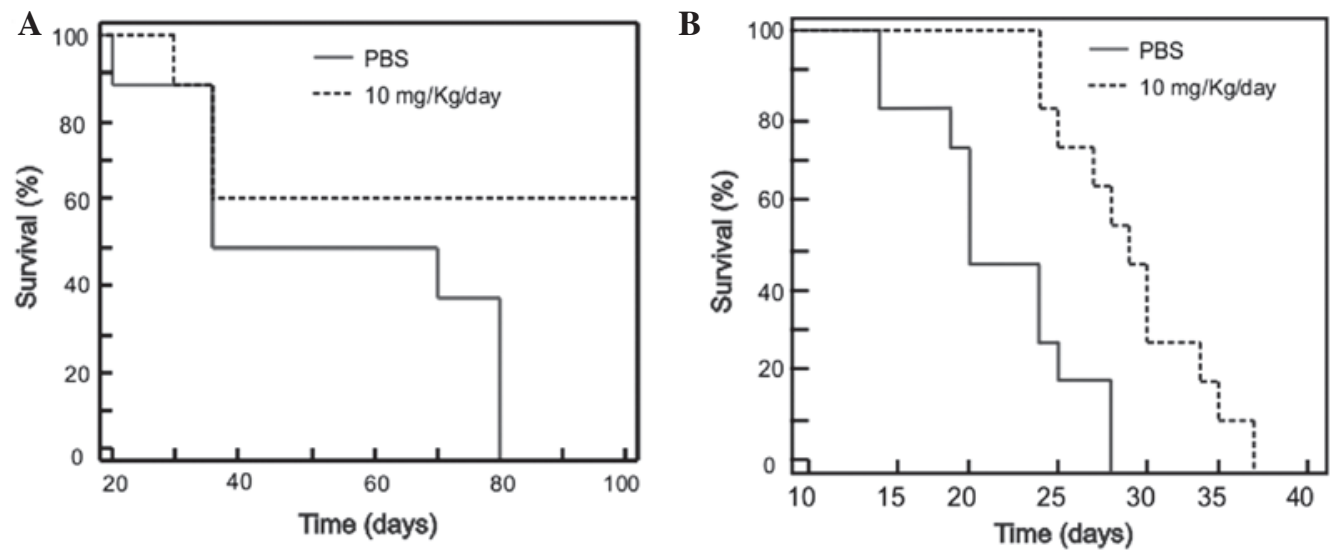

Figure 3. Survival in two animal models with tumors associated with human papilloma virus. (A) A model was generated using HeLa cells in immunodeficient mice, (B) while a second model was generated with TC-1 cells in immunocompetent mice. Mice treated with meclofenamic acid (10 mg/kg/day) survived for a longer period than those treated with saline solution ( $\mathrm{P}=0.001$ and $\mathrm{P}=0.038$ for HeLa and TC-1 models, respectively).

treatment period, and at the day 30 , it was observed that the mice treated with meclofenamic acid presented with tumors that were 4-fold smaller in size than the control mice (administration with saline solution). The difference in the percentage tumor growth curve was statistically significant $(\mathrm{P}=0.0001)$.
As shown in Fig. 2B, the tumor volume growth curve of the mice treated with meclofenamic acid was significantly lower than that of the control group $(\mathrm{P}=0.009)$. By contrast, in the large tumor model using TC-1 cells, the neoplastic growth curve was performed until day 10. Although treatment was 
administered for 25 days, only 10 days of data are indicated in Fig. 2B, as $100 \%$ of the mice were alive during this period. Subsequently, mice began to die. It is noteworthy that although the differences are statistically significant, they are not as marked as those observed in the intitial animal model. It is noteworthy that although the differences are statistically significant, they are not as marked as those observed in the first animal model. In accordance with the previous results of the present study, the survival times of the mice treated with meclofenamic acid were significantly superior to the mice of the control group. The median survival times were 100 vs. 52 days (treated vs. control) for the small tumor model using HeLa cells (Fig. 3A; $\mathrm{P}=0.001$ ), and 29 vs. 19 days for the large tumor model using TC-1 cells (Fig. 3B; $\mathrm{P}=0.038$ ).

\section{Discussion}

Meclofenamic acid was revealed to be an efficient antineoplastic and antitumor agent in in vitro and in vivo models of UCC in the present study. Epidemiological studies have demonstrated that the chronic administration of several individually prescribed NSAIDs reduced the incidence of certain neoplasias $(21,22)$. It has been postulated that the COX-2 inhibition caused by NSAIDs generates anti-proliferative and pro-apoptotic effects in diverse cell lines, which could explain the therapeutic effects found in the present study. Nevertheless, there are few studies on the NSAID effects in UCC. Sulindac, aspirin, ibuprofen and celecoxib have exhibited apoptotic effects in UCC cell lines (in vitro) (23). In the present study, it was confirmed that the meclofenamic acid has a higher cytotoxic effect than sulindac or celecoxib. It is noteworthy that celecoxib, one of the most studied antineoplastic NSAIDs $(16,24)$, did not exhibit an significant effect when compared with meclofenamic acid. This fact is in agreement with the poor benefits found in clinic assays where celecoxib was employed in UCC patients (25).

Notably, the drugs used in the present study (NSAIDs and dexamethasone) exhibited varied antineoplastic effects, which confirms that the inhibition of inflammation is not enough to generate an effect against cancer. The antitumor activity of meclofenamic acid was recently reported in prostate cancer (11). It was proposed that the effect is not only caused by COX-2 inhibition, but also by the strong inhibition of AKRs. Meclofenamic acid is one of the strongest NSAIDs in the inactivation of COX-2, and it is also one of the most efficient to inactivate the AKRs. Therefore, all these observations have lead to the proposition that NSAIDs are a causative mechanism of antineoplastic effects (10).

In the in vitro and in vivo essays in the present study, the highest drug effect was observed in the HeLa (HPV-18+) cells, which have a glandular origin (originally from cervix adenocarcinoma). This fact is in agreement with the suggested proposal that this meclofenamic acid may have stronger activity in neoplasias with a glandular origin (11). Nonetheless, the results of the present study showed the antineoplastic action in human cells of a squamous nature ( $\mathrm{SiHa}, \mathrm{HPV}-16^{+}$). In addition, the same effectiveness was observed when the drug was applied to HPV- $16^{+}$and HPV- $18^{+}$cells. The enhanced action of meclofenamic acid showed significant benefits as a cytotoxic-effect drug in a model in which the treatment was started when the tumors were of a small size, as well as when mice with large tumors were treated. Although the best effect was evidently generated in the small tumor model of HeLa cells, the used models were not comparable; the immunodeficient and the immunocompetent models are characterized by tumor cells with different origins, since they precede from different mouse strains. However, these experiments confirm an antitumor effect even in the different studied models.

The dose employed in the animals, in accordance with previous results (11), did not have systemic toxic effects; in addition, it is notable that the immunodeficient model confirmed that the antitumor effect was caused directly by the drug action, without implicating the immune system.

In conclusion, the present study determined that meclofenamic acid is a potential antineoplastic agent against UCC or HPV-dependent neoplasias. The clinical utility of the drug, possibly as a coadjuvant, requires further investigation in future clinical trials.

\section{Acknowledgements}

The present study was completed with grants provided by SEP-CONACYT via projects 61137 and 226165. The manuscript publication costs were covered in part by support from PIFI-2013 (CA-UAZ-207).

\section{References}

1. Howley P and Lowy D: Papillomaviruses and their replication. In: Fields Virology. Knipe DM and Howley PM (eds). Lippincott Williams \& Wilkins, Philadelphia, PA, pp2197-2229, 2001.

2. Coussens LM and Werb Z: Inflammation and cancer. Nature 420: 860-867, 2002

3. Hold GL and El-omar EM: Genetic aspects of inflammation and cancer. Biochem J 410: 225-235, 2008.

4. Vane J: Towards a better aspirin. Nature 367: 215-216, 1994.

5. FitzGerald GA and Patrono C: The coxibs, selective inhibitors of cyclooxygenase-2. N Engl J Med 345: 433-442, 2001.

6. Gierse JK, Hauser SD, Creely DP, Koboldt C, Rangwala SH, Isakson PC and Seibert K: Expression and selective inhibition of the constitutive and inducible forms of human cyclo-oxygenase. Biochem. J 305: 479-484, 1995.

7. Gruber BM, Bubko I, Krzyszton-Russjan J and Anuszewska EL: Synergistic action of doxorubicin and sulindac in human cervix carcinoma cells - studies on possible mechanisms. Med Sci Monit 16: BR45-BR51, 2010.

8. Crum C, Muovo G and Lee K: The cervix. In: Sternberg S (ed). Diagnostic Surgical Pathology. 3rd edition. Lippincott Williams \& Wilkins, Philadelphia, PA, pp2155-2202 1999.

9. Bauman DR, Steckelbroeck S and Penning TM: The roles of Aldo-Keto reductases in steroid hormone action. Drug News Perspect 17: 563-578, 2004.

10. Bauman DR, Rudnick SI, Szewczuk LM, et al: Development of nonsteroidal anti-inflammatory drug analogs and steroid carboxylates selective for human aldo-keto reductase isoforms: Potential antineoplastic agents that work independently of cyclooxygenase isozymes. Mol Pharmacol 67: 60-68, 2005.

11. Soriano-Hernández AD, Galvan-Salazar HR, Montes-Galindo DA, et al: Antitumor effect of meclofenamic acid on human androgen-independent prostate cancer: A preclinical evaluation. Int Urol Nephrol 44: 471-477, 2012.

12. Rahbari R, Sheahan T, Modes V, Collier P, Macfarlane C and Badge RM: A novel L1 retrotransposon marker for HeLa cell line identification. Biotechniques 46: 277-284, 2009.

13. Watson DM, The Virginian-Pilot: HeLa Cancer cells killed Henrietta Lacks - then made her immortal. http://hamptonroads. com/2010/05/cancer-cells-killed-henrietta-lacks-then-made-herimmortal. Accessed September 17, 2014.

14. Kim KM, Song JJ, An JY, Kwon YT and Lee YJ: Pretreatment of acetylsalicylic acid promotes tumor necrosis factor-related apoptosis-inducing ligand-induced apoptosis by down-regulating BCL-2 gene expression. J Biol Chem 280: 41047-41056, 2005. 
15. Blaheta RA, Weich E, Marian D, Bereiter-Hahn J, Jones J, Jonas D, Michaelis M, Doerr HW and Cinatl J Jr: Human cytomegalovirus infection alters PC3 prostate carcinoma cell adhesion to endothelial cells, and extracellular matrix. Neoplasia 8: 807-816, 2006.

16. Kim SH, Song SH, Kim SG, Chun KS, Lim SY, Na HK, Kim JW, Surh YJ, Bang YJ and Song YS: Celecoxib induces apoptosis in cervical cancer cells independent of cyclooxygenase using NF-kappaB as a possible target. J Cancer Res Clin Oncol 130: 551-560, 2004.

17. Al-Nasiry S, Geusens N, Hanssens M, Luyten C and Pijnenborg R: The use of Alamar Blue assay for quantitative analysis of viability, migration and invasion of choriocarcinoma cells. Hum Reprod 22: 1304-1309, 2007.

18. Stephenson RA, Dinney CP, Gohji K, Ordonez NG, Killion JJ and Fidler IJ: Metastatic model for human prostate cancer using orthotopic implantation in nude mice. J Natl Cancer Inst 84: 951-957, 1992

19. Koziol JA, Maxwell DA, Fukushima M, Colmerauer ME and Pilch YH: A distribution-free test for tumor-growth curve analyses with application to an animal tumor immunotherapy experiment. Biometrics 37: 383-390, 1981.

20. SAGARPA: Technical specifications for the care and use of laboratory animals of the Mexican Official Standard (NOM-062-ZOO-1999). www.fmvz.unam. $\mathrm{mx} / \mathrm{fmvz} / \mathrm{principal/archivos/062ZOO.PDF}$ (In Spanish). Accessed June 17, 2015.
21. QuannEJ,Khwaja F,ZavitzKH and Djakiew D: The aryl propionic acid R-flurbiprofen selectively induces p75NTR-dependent decreased survival of prostate tumor cells. Cancer Res 67: 3254-3262, 2007.

22. Adachi M, Sakamoto H, Kawamura R, Wang W, Imai K and Shinomura Y: Nonsteroidal anti-inflammatory drugs and oxidative stress in cancer cells. Histol Histopathol 22: 437-442 2007.

23. Sakonlaya D, Tapanadechopone P, Poomkokruk A and Charoenvilaisiri S: Do NSAID's Inhibit growth of precancerous cervical cells in vitro? J Med Assoc Thai 95 (Suppl 1): S65-S73, 2012.

24. Wang AH, Tian XY, Yu JJ, Mi JQ, Liu H and Wang RF: Celecoxib radiosensitizes the human cervical cancer HeLa cell line via a mechanism dependent on reduced cyclo-oxygenase- 2 and vascular endothelial growth factor $\mathrm{C}$ expression. J Int Med Res 40: 56-66, 2012.

25. Gaffney DK, Winter K, Dicker AP, Miller B, Eifel PJ, Ryu J, Avizonis V, Fromm M, Small W and Greven K: Efficacy and Patterns of failure for locally advanced cancer of the cervix treated with celebrex (celecoxib) and chemoradiotherapy in RTOG 0128. Int J Radiat Oncol Biol Phys. 69: 111-117, 2007. 